\title{
Effect of Recycled Plastic in Mortar and Concrete and the Application of Gamma Irradiation - A Review
}

\author{
Aliyu Usman ${ }^{l}$, Muslich Hartadi Sutanto ${ }^{1,2 *}$, and Madzlan Napiah ${ }^{l}$ \\ ${ }^{1}$ Department of Civil \& Environmental Engineering, Universiti Teknologi PETRONAS, 32610 \\ Bandar Seri Iskandar, Perak, Malaysia \\ ${ }^{2}$ Institute of Self Sustainable Building, Universiti Teknologi PETRONAS, 32610 Bandar Seri \\ Iskandar, Perak, Malaysia
}

\begin{abstract}
The utilization of a large amount of waste in concrete production is considered the best alternative for solving the issues associated with improper disposal. Plastic waste is considered as one of such waste and could be utilized in several applications. The drawback associated with the utilization of a large amount of plastic waste is the decrease in the mechanical properties of the mortar or concrete as the case may be. This paper presents a detailed review about waste recycled plastics and research published on the effect of non-irradiated recycled plastic on the mechanical properties of cement mortar and cement concretes as either fillers or aggregates and the application of gamma radiation on the recycled plastic waste. The effect of recycled waste plastic on compressive strength, flexural strength and splitting tensile strength is discussed in this paper.
\end{abstract}

\section{Introduction}

Polyethylene terephthalate (PET) is among the commonest type of consumer plastic utilized for storing vessels of beverages and this is because of its favorable properties which are its lightweight, easy to handle and store. PET is commonly used as a raw material in the manufacture of plastic soft drinks bottles and vessels for food packaging and other final goods.

Researches involving several types of plastic have been conducted recently; these include polyethylene terephthalate (PET), high-density polyethylene (HDPE) and polypropylene (PP). On these investigations emphases focus is made on the consequences of plastic addition in the workability of the fresh composites and in the mechanical strength of the hardened composites mixtures. [1-4]. Ismail and AL-Hashmi [5] reported that the increase in workability and decrease in bulk density as a result of an increase in the number of plastic aggregates in the composite mixture (which consist of $80 \%$ polyethylene and $20 \%$ polystyrene) is due to low density of plastic aggregates when compared to

* Corresponding author: muslich.sutanto@utp.edu.my 
conventional aggregate. On the performance of plastic used as soft filler in concrete the application of chemical treatment of post-consumer waste HDPE plastic was employed and has shown to be successful with a significant effect on the performance of the plastic filler [6].

A research was the utilization of car bumper was used as plastic aggregates was conducted by AL-Manaseer and Dalal [7]. In their work, they found out that the ductile behavior of concrete mixtures incorporating plastic aggregates is higher when compared with conventional aggregates. This higher ductile behavior in terms of crack formation in concrete is advantageous because it could minimize the crack propagation. As reported by several studies on the effect of plastic aggregates on compressive and splitting tensile strength, similar trend ware observed as the strengths values were lowered with an addition in the number of plastic aggregates.

Plastic is a very versatile and effective raw material that is cheaper and produced on a large scale. Nowadays, plastic has been virtually revolutionized every vital sector of the economy ranging from agriculture to packaging, automobile, electronics, electrical, building construction and communication sectors. A non-biodegradable material and has been found by many researchers that it can remain on earth for decades and even centuries without degradation. The health hazard caused as a result of improper disposal of plastic waste has been proven and reported by several studies. Reproductive problems in human and animals, genital abnormalities etc were some of the health hazard reported. Looking forward to the scenario of present lifestyle a complete ban on the use of plastic cannot be put, although the plastic waste taking the face of the devil for the present and future generation. Plastic usage cannot be completely abolished but the waste generated from it can be reused as either aggregates, modifiers, additives or fillers in road and building construction industries [8].

Mello et al. [9] reported that one of the most commonly found plastic materials in solid urban waste is polyethylene terephthalate (PET). PET is semi-crystalline thermoplastic polyester commonly found in the form of clear plastic water and carbonated drink bottles. A yearly consumption of 250,000 million PET bottles weighing 10 million tons was reported in 2007 with a growth rate of $15 \%$ per year. Several researchers reported that utilization of PET waste in concrete positively affects the flexural toughness, impact resistance, and workability $[1,10,11]$. However, it also showed a drawback in compressive strength with an increment of PET waste. An essential groundwork conducted by Schaefer et al. [12] found a promising way to improve the compressive strength of cement paste containing powdered PET plastic waste through a combination of adding fly-ash and irradiating recycled PET powder with different dose of gamma irradiation commonly used in food sterilization process. This supports a study by Kattan [13] that gamma irradiation increases the degree of crystallinity of recycled PET. Further research is needed to study the optimal effect of using irradiated recycled PET aggregates and in lightweight concrete.

The re-use of wastes is important from a number of different points of view. Natural resources which are not replenished will be saved and sustain; pollution of the environment will be on the decrease and it also helps to save and recycle energy in production processes. A large amount of polyethylene terephthalate (PET) waste is one of the major environmental issues in many locations in the world. The PET wastes are typically plastic beverage, margarine, shampoo and detergent bottles that are collected after use at many domestic waste sites and landfills.

The production of polyethylene terephthalate (PET) is increasing rapidly and the PET waste is becoming a major environmental concern. PET waste has been utilized in the highway and construction industries as aggregate replacements but as the waste PET content is increased the mechanical properties of the resulting modified mixtures were decreased. However, with the application of gamma irradiation on the waste PET as an 
aggregate replacement in concrete mixtures, it was reported that the mechanical properties increase rapidly as the irradiated waste PET content is increased. Therefore irradiation can be considered as an alternative method to the traditional chemical methods used in modifying the molecular structure of polymers [14]. The effects of gamma irradiation on polymers are usually evaluated through changes in their chemical structure and mechanical behavior. These modifications occur as a result of the reorganization of chemical bonds which allows an increase in the degree of polymerization or structural reticulation. The main reason why polymers are modified is the optimization of its properties and increasing compatibility in composite materials [15].

Gamma rays can be used in modifying the molecular structure of composite materials. It helps immensely in linking and degradation of polymers (by chain scission). The degree to which these processes occur is observed from the chemical composition of the polymer. The polymer which is cross-linked by gamma radiation usually shows superior properties. Therefore, the application of radiation technology is ideal for polymer recycling as it better from an economic and ecological viewpoint.

\section{Types of plastic and plastic waste}

Plastics can be referred to as materials which comprise several types of elements which include nitrogen, carbon, hydrogen, oxygen, chlorine, and sulfur. Plastics are formed through a process called polymerization; this can either be an addition or condensation polymerization. Plastics can be classified based on their physical properties either as thermoplastics or thermosetting plastic materials. Thermoplastics materials are those types of plastic that can be formed into desired shapes under the application of heat and pressure and becomes solid on cooling while thermosetting plastics materials are the types that once shaped cannot be remolded by the application of heat.

Plastic wastes cause eternal problems as the products synthesized from petroleum are non-biodegradable and that is the main reason why plastic wastes remain in landfills without breaking down or changing composition. Some of the problems associated with improper disposal of plastic wastes are polluting the beaches and oceans, littering the landscapes, generation of toxic fumes when burnt and bags made up of plastics kill animals etc. Table 1 details the uses of plastics and recycled plastics [16].

Table 1. Uses of plastics and recycled plastics [16]

\begin{tabular}{|l|l|l|l|}
\hline \multicolumn{1}{|c|}{ Name of plastic } & \multicolumn{1}{|c|}{ Description } & \multicolumn{1}{|c|}{$\begin{array}{c}\text { Uses of virgin } \\
\text { plastic }\end{array}$} & $\begin{array}{c}\text { Uses of plastic } \\
\text { made from recycled } \\
\text { waste Plastic }\end{array}$ \\
\hline $\begin{array}{l}\text { Polyethylene } \\
\text { terephthalate } \\
\text { (PET) }\end{array}$ & $\begin{array}{l}\text { Clear tough } \\
\text { plastic, may be } \\
\text { used as a fiber }\end{array}$ & $\begin{array}{l}\text { Soft drink and } \\
\text { mineral water } \\
\text { bottles, filling for } \\
\text { sleeping bags and } \\
\text { pillows, textile fibers }\end{array}$ & $\begin{array}{l}\text { Soft drink bottles, } \\
\text { (multi-layer) } \\
\text { detergent bottles, } \\
\text { clear film for } \\
\text { packaging, carpet } \\
\text { fibers, fleecy jackets }\end{array}$ \\
\hline $\begin{array}{l}\text { High-density } \\
\text { polyethylene } \\
\text { (HDPE) }\end{array}$ & $\begin{array}{l}\text { Very common } \\
\text { plastic, } \\
\text { usually white or } \\
\text { colored }\end{array}$ & $\begin{array}{l}\text { Crinkly shopping } \\
\text { bags, freezer bags, } \\
\text { milk and cream } \\
\text { bottles, bottles for } \\
\text { shampoo and } \\
\text { cleaners, milk crates }\end{array}$ & $\begin{array}{l}\text { Compost bins, } \\
\text { detergent bottles, } \\
\text { crates, mobile } \\
\text { rubbish bins, } \\
\text { agricultural pipes, } \\
\text { pallets, kerbside }\end{array}$ \\
\hline
\end{tabular}




\begin{tabular}{|c|c|c|c|}
\hline $\begin{array}{l}\text { Unplasticized } \\
\text { polyvinyl } \\
\text { Chloride (UPVC) }\end{array}$ & $\begin{array}{l}\text { Hard rigid plastic, } \\
\text { may be clear }\end{array}$ & $\begin{array}{l}\text { Clear cordial and } \\
\text { juice bottles, blister } \\
\text { packs, plumbing } \\
\text { pipes and fittings }\end{array}$ & $\begin{array}{l}\text { Detergent bottles, } \\
\text { tiles, plumbing pipe } \\
\text { fittings }\end{array}$ \\
\hline $\begin{array}{l}\text { Plasticized polyvinyl } \\
\text { Chloride (PPVC) }\end{array}$ & $\begin{array}{l}\text { Flexible, clear, } \\
\text { elastic } \\
\text { plastic }\end{array}$ & $\begin{array}{l}\text { Garden hose, shoe } \\
\text { soles, blood bags, } \\
\text { and tubing }\end{array}$ & $\begin{array}{l}\text { Hose inner core, } \\
\text { industrial flooring }\end{array}$ \\
\hline $\begin{array}{l}\text { Low density } \\
\text { polyethylene } \\
\text { (LDPE) }\end{array}$ & $\begin{array}{l}\text { Soft, flexible } \\
\text { plastic }\end{array}$ & $\begin{array}{l}\text { Lids of ice-cream } \\
\text { containers, garbage } \\
\text { bags, } \\
\text { garbage bins, black } \\
\text { plastic sheet }\end{array}$ & $\begin{array}{l}\text { Film for builders, } \\
\text { industry, packaging, } \\
\text { and plant } \\
\text { nurseries, bags }\end{array}$ \\
\hline Polypropylene (PP) & $\begin{array}{l}\text { Hard, but flexible } \\
\text { plastic - many } \\
\text { uses }\end{array}$ & $\begin{array}{l}\text { Ice-cream } \\
\text { containers, potato } \\
\text { crisp bags, drinking } \\
\text { straws, hinged lunch } \\
\text { boxes }\end{array}$ & $\begin{array}{l}\text { Compost bins, } \\
\text { kerbside recycling } \\
\text { crates, worm } \\
\text { Factories }\end{array}$ \\
\hline Polystyrene (PS) & $\begin{array}{l}\text { Rigid, brittle } \\
\text { plastic. Maybe } \\
\text { clear, glassy }\end{array}$ & $\begin{array}{l}\text { Yoghurt containers, } \\
\text { plastic cutlery, } \\
\text { imitation crystal } \\
\text { "glassware", }\end{array}$ & $\begin{array}{l}\text { Clothes pegs, coat } \\
\text { hangers, office } \\
\text { accessories, spools, } \\
\text { rulers, video/CD } \\
\text { boxes }\end{array}$ \\
\hline $\begin{array}{l}\text { Expanded } \\
\text { polystyrene } \\
\text { (EPS) }\end{array}$ & $\begin{array}{l}\text { Foamed, } \\
\text { lightweight, } \\
\text { energy absorbing, } \\
\text { thermal insulation }\end{array}$ & $\begin{array}{l}\text { Hot drink cups, } \\
\text { takeaway food } \\
\text { containers, meat } \\
\text { trays, packaging }\end{array}$ & \\
\hline
\end{tabular}

\subsection{Utilization of waste/recycled plastics}

There is a wide range of utilization of plastic. Some plastics such as food packaging plastics becomes waste in a short time after been purchased and used, while other types of plastic items are re-used several times over before been thrown to the environment as waste. Plastics are easily re-usable when compared to recycling as the process of recycling consumes a huge amount of capital energy and resources. According to EPA [17], in the United States, $80 \%$ of post-consumer plastics waste is sent to the landfill, $8 \%$ is incinerated and only $7 \%$ is recycled. Plastic re-use greatly helps in decreasing the amount of plastic waste that requires disposal and recycling plastic can have several other merits which include:

1. Conservation of non-renewable fossil fuels;

2. the plastic production uses $8 \%$ of the world's oil production, $4 \%$ as feedstock and $4 \%$ during manufacture;

3. Reduced consumption of energy;

4. Reduced amounts of solid waste going to landfill; and

5. Reduced emissions of carbon dioxide $\left(\mathrm{CO}_{2}\right)$, nitrogen oxide (NO) and sulfur dioxide $\left(\mathrm{SO}_{2}\right)$.

\subsection{Merits of waste/recycled plastic}

Merits of using waste/recycled plastics are: 
1. Municipal solid wastes in landfilled are reduced and

2. It will serve as an alternative to pressure-treated lumber that released chemicals into the water which are toxic.

\section{Mechanical Properties of cement concrete and cement mortars incorporating plastic wastes}

\subsection{Compressive, flexural and splitting strength tests}

Among these properties, concrete categorization largely depends on comprehensive strength. Knowing the comprehensive strength of the original concrete is paramount when considering its replacement with other materials. The term flexural strength refers to the ability of a structure to withstand bending failure. It is mostly evaluated either by 3 or 4 point loading test. In order to understand the behavior of a concrete, calculating the split tensile strength is needed. However, it is difficult to measure tensile strength directly. In fact, applying an axial load in direction tension is almost impossible. As such it is important to study the behavior of concrete in tension by indirect testing. One good method of indirect testing is split tensile method. Addition/replacement of various types of plastic materials can be considered for increasing the strength as discussed below.

\subsubsection{Mechanical properties of cement concrete incorporating plastic wastes}

Hannawi et al., [18] investigated the effect of using polyethylene terephthalate (PET) and polycarbonate (PC) aggregates on the physical and mechanical properties of mortars and concrete and found out that the compressive strengths values decreased for both mixtures with an increase in the amount of the two types of plastic aggregates for each mixture type. The replacement levels adopted for both mixtures were 3\%,10\%,20\% and 50\% for both types of plastic aggregates and the reduction in compressive strengths were observed to be $9.8 \%, 30.5 \%, 47.1 \%$ and $69 \%$ for PET aggregates and 6.8\%, $27.2 \%, 46.1 \%$ and $63.9 \%$ for PC aggregates as per the replacement levels respectively. The reduction in compressive strengths values was attributed to poor or weak bonding between the cement paste and the plastic aggregates. On the other hand, the flexural strength values when compared with that obtained for the reference mixture has no significant effect for mixtures having plastic aggregates up to $10 \%$ PET and $20 \%$ PC. This trend is attributed to the non-brittle and elasticity characteristics of plastic aggregates under loading.

Based on the investigation reported by [5] on waste plastic as an aggregate in concrete, a decrease in strength of plastic the mixture was observed with increasing the amount of the waste at each curing age. The reason for the decreased observed was attributed to the adhesive strength reduction between the cement paste and the waste plastic surface coupled to an increased particle size of waste plastic. Another factor that may likely hinder the hydration of the concrete structure during the curing time was the hydrophobic nature of the plastic. A similar observation was found as the flexural strength values decreased as the compressive strength of the waste plastic content is increased. Addition of waste plastic as a replacement of sand in concrete largely affects the rate of hydration which is slightly developed with time. These findings agree with the results reported by $[2,19]$ which clearly shown a slight decreased increase compressive strength of composites as the sand volume substituted in the aggregates increased.

The effects of inclusion of plastic aggregates on the compressive strength of concrete were reported by Al-Manaseer and Dalal [7]. From the result of the findings, it was revealed that the compressive strength of concrete mixtures decreased with an increased in 
plastic aggregates content. They also found a decreased in compressive strength of the concrete mixtures which was incorporated with plastic aggregates at all levels, as the water cement ratio is increased. This phenomenon observed was due to the inclusion of plastic aggregates, might result in a poor bond between cement paste and the plastic aggregates or it could be as a result of the low strength of the plastic aggregates. It was pertinent to notice that the fractured surface of the concrete cylinder the plastic aggregates pulled out rather than splitting apart due to the plastic aggregate in the mixture. With regard to the conventional or reference concrete, an observation for the failure of typical normal brittle type was observed, however, for the plastic aggregates mixture, the brittle type of failure under compression load did not. Depending on the plastic aggregates content, this failure was more of a gradual type. An increased in the number of plastic aggregates in the mixture led to more ductility of the failure. The corresponding increase in the percentage of plastic aggregate in the concrete mixture resulted in more stability of the material to withstand load without complete break up for minutes.

The effect of using ground plastic on the compressive strength of concrete was investigated by Batayneh et al., [20] The outcome of the study revealed a drastically decreased in the strength of concrete incorporating the ground plastic as a fine aggregate replacement with an increase in the content of plastic in the mixture. This decreased in strength exhibited a drastic increase from $23 \%$ reduction at $5 \%$ replacement to $72 \%$ reduction at $20 \%$ replacement. However, the flexural and splitting tensile strength values were observed to show a similar pattern in behavior with the compressive strength with a lower effect. These observed behaviors were attributed to the fact that the amount of fine aggregate strength is higher than the plastic strength. As such, incorporation of plastic particles in concrete mixtures should be well controlled in order to achieve mixtures within the allowable strength of structural elements. From the investigation of Choi et al., [1], the used of polyethylene terephthalate (PET) bottles for the manufacture of lightweight aggregates (WPLA), compressive and splitting tensile strengths decreased with an increase in the level of replacement. From the study of the effect on the compressive and splitting tensile strengths, different water-cement $(\mathrm{w} / \mathrm{c})$ ratios were employed for replacement levels of $0 \%, 25 \%, 50 \%$ and $75 \%$ by volume of fine aggregates. A similar trend was seen for compressive and splitting tensile strengths decreases with an increase in the level of replacement. However, for a particular PET aggregate, an increased in the strength with a decrease in w/c ratio was reported. Another study conducted by Marzouk et al., [2] reported a substitution of fine aggregates with consumed plastic bottle waste. Bottles made of PET were employed as partial and complete substitutions for fine aggregates in concrete mixtures in the work. The substitute for sand by volume with PET aggregates was used varying the sand fraction from $2 \%$ to $100 \%$ with an equal volume of granulated plastic. From the results obtained, it was revealed that granulated PET of maximum size $5 \mathrm{~mm}$ as a substitute of sand below $50 \%$ by volume does not affect the compressive strength or the flexural strength of the resulting concrete specimen.

\subsubsection{Mechanical properties of cement mortar incorporating plastic wastes}

Wicaksono et al., [21] in their work on the use of recycled PET as fillers for paving block application found out that the compressive and flexural strengths of the cement/sand/PET composite materials increase up to a specific replacement amount 0 f $20 \%$ and after which the strengths were drastically reduced. The increment in compressive strengths, when compared with the reference composite mixtures, was about $26.38 \%$ for $20 \%$ volume of PET filler. This behavior was attributed to the densification which occurs during the curing process for a higher percentage of PET filler in the composite mixture, PET in the mixture obstruct the phase formation within the cement matrix. However, the density and water 
absorption of the composite were decreased as the PET fillers content is increased. The highest values for density and water absorption were found in the control mixtures and the minimum recorded for the composite with $100 \%$ PET filler. Table 2 below shows the water absorption, density, compressive and flexural strengths.

Table 2. Compressive and flexural strengths, density and water absorption test results (Wicaksono et al., [21])

\begin{tabular}{|c|c|c|c|c|c|c|c|}
\hline $\begin{array}{c}\text { Percentage } \\
\text { of } \\
\text { replacement }\end{array}$ & 0 & 10 & 20 & 30 & 40 & 50 & 100 \\
\hline $\begin{array}{c}\text { Compressive } \\
\text { strength } \\
\text { (MPa) }\end{array}$ & 21.57 & 24.38 & 27.26 & 15.12 & 9.04 & 6.75 & 5.32 \\
\hline $\begin{array}{c}\text { Flexural } \\
\text { strength } \\
\text { (MPa) }\end{array}$ & 1.55 & 1.93 & 2.21 & 1.38 & 1.23 & 1.15 & 0.96 \\
\hline $\begin{array}{c}\text { Density } \\
\text { (kg/m }\end{array}$ & 2.73 & 2.57 & 2.50 & 2.42 & 2.34 & 2.27 & 1.81 \\
\hline $\begin{array}{c}\text { (Mater } \\
\text { absorption } \\
\text { (\%) }\end{array}$ & 10.00 & 8.70 & 7.40 & 6.90 & 6.50 & 5.10 & 1.50 \\
\hline
\end{tabular}

Safi et al., [22] in their study on self-compacting mortar using plastic waste as fine aggregates substitutes prepared a mortar prismatic beam specimens measuring $140 \mathrm{mmx} 140 \mathrm{~mm} \times 160 \mathrm{~mm}$ and the flexural strengths values were observed to decrease with increase in the substitution level, likewise the compressive strength values decreased with increase in the plastic aggregate content in the mixture using the auxiliary steel platens of dimensions $40 \mathrm{mmx} 40 \mathrm{~mm}$ cross-section and with at-least thickness of $10 \mathrm{~mm}$. The decrease in compressive strength was attributed to either poor bonding between the cement paste and plastic aggregates or the low strengths of the plastic aggregates as compared the conventional fine aggregates. For the flexural strength values, the decrease was attributed to the low resistance characteristics of the plastic aggregates in the mixture. Reis and Carneiro, [23] prepared a mortar with 1:3 mix ratio using epoxy polymers mortars (PME) and unsaturated polyester polymer mortars (PMP) as fine aggregate in mortar, their findings revealed that the incorporation of shredded PET waste causes a reduction in the specific weight of the polymer mortars and significantly affects the flexural and compressive strengths values to decrease also with an increase in the number of plastic wastes. Iucolano et al., [24] manufacture mortars incorporating recycled plastic aggregates 
and the study conducted revealed that the strengths values decreased as the waste plastic content is increased, this finding agrees with all the literature reviewed to the best of my knowledge. The reductions in compressive and flexural strengths for $5 \%$ replacement were $48.5 \%$ and $48.4 \%$ respectively. For $15 \%, 20 \%$ and $25 \%$ the reduction in compressive and flexural strengths were $66.0 \%$ and $60.5 \% ; 75.7 \%$ and $62.0 \% ; 84.9 \%$ and $79.1 \%$ respectively. The decrease was attributed to the weak bonding between the cement matrix and the surface of the plastic aggregate. The table below shows the mechanical properties as per Iucolano et al., [24].

Table 3. Mechanical properties of manufactured mortars (Iucolano et al., [24])

\begin{tabular}{|c|c|c|}
\hline $\begin{array}{c}\text { Percent replacement } \\
\text { (\%) }\end{array}$ & $\begin{array}{c}\text { Compressive strength } \\
\text { (MPa) }\end{array}$ & $\begin{array}{c}\text { Flexural strength } \\
\text { (MPa) }\end{array}$ \\
\hline 0 & $5.55 \pm 0.07$ & $2.15 \pm 0.10$ \\
\hline 10 & $2.86 \pm 0.07$ & $1.11 \pm 0.10$ \\
\hline 15 & $1.89 \pm 0.07$ & $0.85 \pm 0.02$ \\
\hline 20 & $1.35 \pm 0.03$ & $0.60 \pm 0.01$ \\
\hline 25 & $0.84 \pm 0.03$ & $0.45 \pm 0.01$ \\
\hline
\end{tabular}

\section{Influence of the application of gamma irradiation on recycled plastic in concrete.}

There are several types of treatment for polymers related materials; this includes electron beam radiation (E-beam), and gamma radiation etc.

Electron beam (e-beam) radiation is a form of ionizing energy that is generally characterized by limited penetration power, high dosage rates, and negatively charged. In the treatment of polymers with e-beam process, there are no additives required and it does not generate any hazardous chemical by-products. Crosslinking by e-beam is done on polymers that are not easy to crosslink chemically.

The radioactive disintegration of some atomic nuclei leads to a production of gamma rays. Among the most widely accepted definition of gamma rays are photons of electromagnetic radiation which are emitted from an atomic nucleus. This type of electromagnetic radiations usually has a higher energy and shorter wavelength compared to $\mathrm{X}$-rays. Typically the wavelength is approximately one-tenth of a nanometer with the much higher energy of thousand electron volts $(\mathrm{eV})$ [25]. 
Gamma radiation has a promising application for PET recycling. It helps immensely in increasing the mechanical properties of concrete and modifies the surface of the structure. It has also profound application in monomer polymerization for ceramic production through initiation and speeds up the reaction. It also helps in improving the adhesion of fiber and matrix [26]. The main mechanical properties usually analyzed in concrete are the compression and impact strength, deformation in the yield point and breakdown, deformation values, strain and modulus of elasticity.

According to a research conducted by Ochbelagh et al., [27] on the effect of gamma and lead as an additive on the resistance and strength of concrete, it was reported that concrete strength increased when subjected to irradiation during solidification of the concrete. The micropores in the concrete are removed by gamma radiation during the solidification. Comparisons were made for the strength in compression of concrete specimens made with sand and without sand were determined for irradiated and non-irradiated samples. The result shows an increase in strength for the irradiated specimen when compared with nonirradiated specimens. The increased in the strength may be attributed to the gamma effect.

Table 4. Compressive strength of irradiated and non-irradiated specimens (Ochbelagh et al.,[27])

\begin{tabular}{|l|l|}
\hline Non-irradiated $\left(\mathbf{k g} / \mathbf{c m}^{2}\right)$ & \multicolumn{1}{|c|}{ Irradiated $\left(\mathbf{k g} / \mathbf{c m}^{2}\right)$} \\
\hline 155 (with sand) & 273 (with sand) \\
\hline 145 (without sand) & 241 (without sand) \\
\hline
\end{tabular}

Report from Martínez- Barrera et al., [28-30] suggested that, adding a plastic to concrete causes reduction in the strength of the concrete. However, this can be recovered by the application of irradiation. The use of gamma irradiation is said to improve the strength properties of the concrete. PET is semi-crystalline polyester with a microstructure that exhibited isotropic properties. It also possessed glassy amorphous compositions [31]. As such PET is among one of the most widely studied polymers. The two effects, Chain scission, and cross-linking are very important for PET upon irradiation [32]. As a result of chain scission effect, it has been shown that the degree of crystallinity in PET is higher upon irradiation by gamma rays [13]. Increase in chain scission as the dose increases cause a decrease in molecular weight. This decreased in molecular weight have led to enhancement of molecular mobility, which promotes the way the molecules are arranged in crystalline structures. Upon irradiation of gamma rays on PET, the mobility increased as a result of chain scission which brings about higher crystallizability. Demirel et al., [33] finds out that there was a positive effect on various mechanical properties of PET and they depend on the magnitude of crystallinity. With higher crystallinity in PET, there was a modification of several properties which are higher modulus, toughness, stiffness, strength, and hardness. On the On the other hand, crosslinking can be referred to as the bonding of one polymer chain to another chemically [32]. The chemical structure of compounds can be strengthened by cross-linking which can be induced by radiation. Thus, both chain scission and cross-linking (which occur simultaneously) in PET can result in enhanced strength.

Without applying irradiation, no increased in the bending strength of the carbonated sample was observed. However, for the carbonated sample subjected to irradiation, increased in bending strength was recorded. Water vapor sorption isotherm data indicated the pseudomorph of $\mathrm{C}-\mathrm{S}-\mathrm{H}$. Measurements conducted by field-emission scanning electron microscopy (FESEM) and small angle X-ray scattering (XRD) supported the conclusion. It was observed that under irradiation, a mineral of calcium carbonate polymorph $\left(\mu-\mathrm{CaCO}_{3}\right)$ called vaterite is formed near calcium hydro-silicate $(\mathrm{C}-\mathrm{S}-\mathrm{H})$ and fills the small pores in it. 
This helps in maintaining the structure of the material by preserving its fractal dimension of the original structure as compared to the ordinarily carbonated samples. Thus, it could be concluded, the strength of the hexagonal closed packed structure (hcp) is improved by gamma-ray-induced carbonation with the formation of vaterite [34]

Martinez-Barrera et al., [30] in their work reported that in order to save money and time, non-destructive and portable (hammer) test were done for non-irradiated concretes than the use of laboratory tests. Also, enhancement in the strength and compressive modulus of polypropylene (PP) fibers reinforced concrete was achieved by the used of gamma irradiation. The level of enhancements depends on polypropylene fiber concentrations, marble particle sizes, and applied irradiation doses. Improvement of mechanical parameters by the application of gamma irradiation doses up to 50kGy was reported and between the components and the hydrated cement phase the ionizing energy from gamma irradiation generates more surface contacts.

The mechanical property of hardened cement mortar and cement concrete are very important in determining the design parameters, safety and economy of structures. This property is affected in most cases when supplementary cementitious materials are incorporated into the mixes, thus there is a critical need to improve such materials for better interactions within the matrix. One of the methods used to modify the crystalline structure by cross-linking and chain scission is by gamma irradiation, as the degree of crystallinity increases and the plastic, in this case, will be tougher, stiffer and harder than the unirradiated plastic waste. Therefore, application of gamma radiation on waste plastic before used as either cement or aggregates substitute is very important as the strength loss while a large amount of waste plastic is used will be recovered and even better.

\section{Conclusions and recommendation}

Based on the literature reviewed, it was discovered that the strengths of mortars and concrete were not enhanced effectively when plastic wastes are added to the mixtures. These drawbacks were found when higher percentages of plastic are used in the mixtures as the flexural, compressive and splitting tensile strengths were decreased with increase in the amount of the waste. However, it is useful to treat plastic with the application of gamma irradiation to get back the strengths lost when non-irradiated plastic is used as fillers, fines, and aggregates in cement paste and cement concrete mixtures. In this case, the treated plastic will enhance the bonding between the cement paste and the plastic aggregates which will greatly affect the strengths of the resulting composites.

Addition of plastics in concrete causes a decrease in the compressive strength of the concrete. However, by using suitable mineral admixtures [1, 5, 35] and chemically treated plastic such as alkaline bleach treatment (bleach $\mathrm{p} \mathrm{NaOH}$ ) [6] the performance of plastic fiber reinforced concrete can be improved

Only a small amount of plastic waste incorporated in concrete yielded little or no enhancement on the tensile strength. [20]. The small improvement in the tensile strength is as a result of the bridging effects of the fibers from the plastic waste in the concrete.

Concrete mixtures reinforced with plastic fiber can be utilized in structures where heavy loads are not anticipated. This will also help to reduce the problem of improper disposal of the waste.

Replacing aggregates with plastic aggregates resulted into a concrete mix with reducing compressive and tensile strength which occur as a result of a weak bond between the plastic and the surrounding matrix. The weak bond that causes a reduction in compression and tension strengths could also be as a result of the failure nature in concrete which propagates in tension. The process of exposing the plastic waste to doses of gamma radiation using cobalt- 60 gamma radiator will cause an increase in the degree of crystallinity of the plastic 
in a way that the material becomes stronger, stiffer and tougher and thereby increasing the mechanical properties of the mortar or concrete mixtures.

Further research is necessary on the use of treated plastic waste (irradiated) with the process of gamma radiation before a large amount of plastic can be considered for widespread use in cement paste and cement concrete structural elements without the drawback associated as discussed above.

The authors would like to thank Universiti Teknologi PETRONAS for the support in this research.

\section{References}

1. Choi, Y.-W., et al., Effects of waste PET bottles aggregate on the properties of concrete. Cement and concrete research, 35(4): p. 776-781 (2005).

2. Marzouk, O.Y., R. Dheilly, and M. Queneudec, Valorization of post-consumer waste plastic in cementitious concrete composites. Waste management, 27(2): p. 310-318 (2007).

3. Sobhan, K. and M. Mashnad, Tensile strength and toughness of soil-cement-fly-ash composite reinforced with recycled high-density polyethylene strips. Journal of Materials in Civil Engineering, 14(2): p. 177-184 (2002).

4. Vaverka, J.V., An analysis of reinforced concrete composites utilizing recycled polyethylene terephthalate thermoplastic. (1993).

5. Ismail, Z.Z. and E.A. Al-Hashmi, Use of waste plastic in concrete mixture as aggregate replacement. Waste Management, 28(11): p. 2041-2047 (2008).

6. Naik, T., et al., Uso di scary plastic post-utilization nel cement a base di material composite. Cement and Concrete Composites, 26: p. 1489-1492 (1996).

7. Al-Manaseer, A. and T. Dalal, Concrete containing plastic aggregates. Concrete International, 19(8): p. 47-52 (1997).

8. Verma, S.S., Roads from Plastic Waste. The Indian Concrete Journal, p. 43-44 (2008).

9. de Mello, D., S.H. Pezzin, and S.C. Amico, The effect of post-consumer PET particles on the performance of flexible polyurethane foams. Polymer Testing, 28(7): p. 702708 (2009).

10. Pelissier, F., et al., Mechanical properties of recycled PET fibers in concrete. Materials Research, 15(4): p. 679-686 (2012).

11. Kim, S.B., et al., Material and structural performance evaluation of recycled PET fiber reinforced concrete. Cement and concrete composites, 32(3): p. 232-240 (2010).

12. Schaefer, C.E., et al., Irradiated recycled plastic as a concrete additive for improved chemo-mechanical properties and lower carbon footprint. Waste Management, 71: p. 426-439 (2018).

13. Kattan, M., Thermal behavior of gamma-irradiated amorphous poly (ethylene terephthalate) films. Polymer Engineering \& Science, 46(10): p. 1374-1377 (2006).

14. Spadaro, G. and A. Valenza, Influence of the irradiation parameters on the molecular modifications of an isotactic polypropylene gamma-irradiated under vacuum. Polymer degradation and stability, 67(3): p. 449-454 (2000).

15. Martínez Barrera, G., et al., Recent Developments in Polymer Recycling. En: Gamma Rays: Technology Applications and Health Implications. (2013).

16. Recycling and Resource Recovery Council, Uses of plastics and recycled plastics. 1994: Australia.

17. EPA, Report on Plastics, USA. (2003).

18. Hannawi, K., S. Kamali-Bernard, and W. Prince, Physical and mechanical properties of mortars containing PET and PC waste aggregates. Waste management, 30(11): p. 2312-2320 (2010). 
19. Pezzi, L., et al. Concrete products with waste's plastic material (bottle, glass, plate). in Materials Science Forum. Trans Tech Publ. (2006).

20. Batayneh, M., I. Marie, and I. Asi, Use of selected waste materials in concrete mixes. Waste management, 27(12): p. 1870-1876 (2007).

21. Wicaksono, S.T., H. Ardhyananta, and A. Rasyida. Study on mechanical and physical properties of composite materials with recycled PET as fillers for paving block application. in AIP Conference Proceedings. AIP Publishing (2018).

22. Safi, B., et al., The use of plastic waste as fine aggregate in the self-compacting mortars: Effect on physical and mechanical properties. Construction and Building Materials, 43: p. 436-442 (2013).

23. Reis, J. and E. Carneiro, Evaluation of PET waste aggregates in polymer mortars. Construction and Building Materials, 27(1): p. 107-111 (2012).

24. Iucolano, F., et al., Recycled plastic aggregate in mortars composition: Effect on physical and mechanical properties. Materials \& Design (1980-2015), 52: p. 916-922. (2013).

25. Bagher, A.M., Advantages of gamma radiation in science and industry. Journal of Advanced Physics, 3(2): p. 97-103 (2014).

26. Patel, M., et al., Gamma radiation induced effects on silica and on silica-polymer interfacial interactions in filled polysiloxane rubber. Polymer Degradation and Stability, 91(2): p. 406-413 (2006).

27. Ochbelagh, D.R., S. Azimkhani, and H.G. Mosavinejad, Effect of gamma and lead as an additive material on the resistance and strength of concrete. Nuclear Engineering and Design, 241(6): p. 2359-2363 (2011).

28. Martínez-Barrera, G., et al., Mechanical improvement of concrete by irradiated polypropylene fibers. Polymer Engineering \& Science, 45(10): p. 1426-1431 (2005).

29. Martínez-Barrera, G., et al., Concrete reinforced with irradiated nylon fibers. Journal of materials research, 21(2): p. 484-491 (2006).

30. Martínez-Barrera, G., et al., Mechanical properties of polypropylene-fiber reinforced concrete after gamma irradiation. Composites Part A: Applied Science and Manufacturing, 42(5): p. 567-572 (2011).

31. Jog, J., Crystallization of polyethyleneterephthalate. Journal of Macromolecular Science, Part C: Polymer Reviews, 1995. 35(3): p. 531-553 (1995).

32. Plester, D.W., Effects of radiation sterilization on plastics, in Industrial sterilization. (1973).

33. Demirel, B., A. Yaraş, and H. Elçiçek, Crystallization behavior of PET materials. Balıkesir Üniversitesi Fen Bilimleri Enstitüsü Dergisi, 13(1): p. 26-35 (2016).

34. Maruyama, I., et al., Impact of gamma-ray irradiation on hardened white Portland cement pastes exposed to atmosphere. Cement and Concrete Research, 108: p. 59-71 (2018).

35. Choi, Y.W., et al., Characteristics of mortar and concrete containing fine aggregate manufactured from recycled waste polyethylene terephthalate bottles. Construction and Building Materials, 23(8): p. 2829-2835 (2009). 